\title{
O Uso do Conhecimento na Sociedade*
}

\author{
Friedrich August von Hayek
}

\begin{abstract}
Resumo: Hayek discute neste artigo que tipo de conhecimento deve ser utilizado nas ciências sociais, especialmente na Economia. Mostra que no mundo real o dito "conhecimento científico" falha na coordenação da atividade econômica e que o conhecimento "prático", ou das circunstâncias de tempo e espaço, é que é relevante nas decisões dos agentes econômicos.
\end{abstract}

Palavras-chave: Imperfeição do Conhecimento, Sociedade, Ciências Sociais, Sistema de Preços, Planejamento, Circunstâncias de Tempo e Espaço.

\section{The Use of Knowledge in Society}

\begin{abstract}
In this article Hayek questions what kind of knowledge must be used in Social Sciences, especially in Economics. He shows that in the real world, the so said "scientific knowledge" failed to promote the coordination of economic activity. He also states that the "practical" knowledge, or the circumstances of time and space, is the relevant kind of knowledge for the economic agents' decisions.
\end{abstract}

Keywords: Imperfection of Knowledge, Society, Social Sciences, Pricing System, Planning, Circumstances of Time and Space.

Classificação JEL: D4, B25, B53

\footnotetext{
"O artigo foi publicado originalmente com o título "The Use of Knowledge in Society" em setembro de 1945 na American Economic Review, v. 35, n. 4, p. 519-30, sendo reeditado como quarto capítulo do livro: HAYEK, F. A. von. Individualism and Economic Order, University of Chicago Press, 1948.

Traduzido do inglês para o português por Philippe A. Gebara Tavares.

${ }^{*}$ Friedrich August von Hayek nasceu em Viena, no dia 8 de maio de 1899, na ocasião, ainda Império AustroHúngaro. Recebeu os títulos de doutor em Direito (1921) e Ciência Política (1923) pela Universidade de Viena, onde também estudou Filosofia, Psicologia e Economia. Com a ajuda de Ludwig von Mises (1881-1973), no final da década de 1920, fundou e dirigiu o Austrian Institute for Business Cycle Research, antes de ingressar na London School of Economics em 1931. Tornou-se súdito inglês em 1938 e, em março de 1944, lançou seu famoso livro $O$ Caminho da Servidão (Instituto Ludwig von Mises Brasil, 2010). Viveu na Grã-Bretanha até 1950 e depois mudou-se para os Estados Unidos, onde permaneceu de 1950 a 1962. Em 1974, recebeu o Prêmio Nobel de Economia pode sua Teoria da Moeda e flutuações econômicas. Faleceu em 23 de março de 1992, em Freiburg, na Alemanha, onde vivia desde a década de 1960.
} 
Qual problema queremos resolver quando tentamos construir uma ordem econômica racional? Em determinadas hipóteses bem familiares, a resposta é assaz simples: se possuímos todas as informações relevantes, se podemos começar a partir de um dado sistema de preferências, e se dominamos completamente o conhecimento dos meios disponíveis, o problema que permanece é puramente de ordem lógica. Isto é, a resposta para a questão sobre qual seria o melhor uso dos meios disponíveis está implícita em nossas hipóteses. Assim, as condições que a solução desse problema "ótimo" 1 devem satisfazer já teriam sido totalmente resolvidas ou, sido mais bem expressas em fórmula matemática, mas resumindo-as da forma mais breve possível, diríamos que as taxas marginais de substituição entre duas commodities ou fatores têm de ser as mesmas em todos os diferentes usos.

Este, contudo, não é - enfatizamos - o problema econômico que a sociedade enfrenta. $\mathrm{O}$ cálculo econômico que desenvolvemos para resolver este problema lógico, embora seja um passo importante para sua resolução, ainda não nos fornece uma resposta. A razão para tal é que os "dados de input" 2 a partir dos quais o cálculo econômico começa nunca são "dados", nem poderiam sê-los, a uma única mente que poderia desenvolver as suas implicações em benefício de toda a sociedade.

O caráter peculiar do problema da ordem econômica racional é determinado precisamente pelo fato de que o conhecimento das circunstâncias, do qual devemos fazer uso, nunca existe de uma forma concentrada ou integrada, mas apenas como bits dispersos

\footnotetext{
${ }^{1}$ Isto é, a maior eficiência exequível. (N. do T.)

2 Preferiu-se aqui traduzir o termo inglês "data" por "dados de input" para evitar a ambiguidade que se poria em relação à tradução do termo "given", que aparece logo depois. Este deve ser traduzido pelo adjetivo plural "dados", o qual, por sua vez, coincidiria ortograficamente com o primeiro, que é substantivo, caso fosse traduzido literalmente como os "dados", em contraposição a algo "dado". (N. do T)
}

daquele conhecimento incompleto e frequentemente contraditório que todos os indivíduos isolados possuem. O problema econômico da sociedade não é, portanto, somente um problema de como alocar recursos "dados" se por "dado" entende-se aquilo que é dado a uma única mente que resolveria reflexivamente o problema posto pelos "dados de input". É mais a questão de como assegurar o melhor uso dos recursos conhecidos para todos os membros da sociedade, para fins cuja importância relativa apenas estes indivíduos conheceriam. Ou, para sintetizar, este é um problema sobre a utilização do conhecimento que não é dado a ninguém em sua totalidade.

Essa característica de nosso problema fundamental tem sido obscurecida, para minha preocupação, em vez de ser iluminada por muitos dos recentes aperfeiçoamentos em teoria econômica, especialmente pelos variados usos da Matemática. Embora o problema do qual queira por princípio tratar neste artigo seja aquele da organização econômica racional, deverei, em seu curso, ser levado diversas vezes a apontar suas estreitas ligações com certas questões metodológicas. Muitos pontos a que quero fazer menção são, na verdade, conclusões para as quais diversos caminhos da reflexão inesperadamente convergiram. Porém, uma vez que no momento vislumbro tais problemas, esse percurso não é nenhum acidente: parece-me que muitas das discussões atuais a respeito tanto da teoria econômica, quanto da política econômica, têm origem comum em um equívoco sobre a natureza do problema econômico da sociedade. Esse equívoco, por sua vez, é causado por uma transferência indevida aos fenômenos sociais daqueles hábitos de pensamento que viemos desenvolvendo em nossa lida com os fenômenos da natureza.

\section{II}

$\mathrm{Na}$ linguagem comum, descrevemos com a palavra "planejamento" aquele complexo de decisões inter-relacionadas sobre 
a alocação dos recursos disponíveis. Toda a atividade econômica é, neste sentido, planejamento; e em toda sociedade na qual muitas pessoas colaboram, este planejamento, quem quer que o faça, terá de ser baseado, em alguma medida, no conhecimento. Este, em primeira instância, não é dado para o planejador, mas para uma outra pessoa, que, de algum modo, terá de ser reconduzido para o planejador. As várias maneiras pelas quais o conhecimento em que as pessoas baseiam os seus planos lhes são comunicadas constituem o problema crucial de toda teoria que queira explicar o processo econômico, e o problema sobre como utilizar, da melhor maneira possível, o conhecimento, inicialmente disperso entre todas as pessoas, é uma das principais questões da política econômica - ou do projeto de um sistema econômico eficiente.

A resposta a esta questão está intimamente ligada a outra questão que surge aqui, a de quem deve fazer o planejamento. É em torno dessa questão que toda discussão sobre "planejamento econômico" gira. Não é uma discussão sobre se o planejamento deve ser feito ou não: é uma disputa sobre se o planejamento deve ser feito de forma centralizada, por uma única autoridade e cobrindo todo o sistema econômico, ou se é para ser dividido entre vários indivíduos. Planejamento no sentido específico em que o termo é usado no debate contemporâneo significa, necessariamente, planejamento central - que dirige todo o sistema econômico de acordo com um plano unificado. Competição, por outro lado, significa planejamento descentralizado por várias pessoas distintas. O ponto de transição entre os dois, sobre o qual muitas pessoas falam, mas do qual poucos gostam quando veem, é a delegação do planejamento a indústrias organizadas, ou, em outras palavras, aos monopólios.

Qual desses sistemas tenderá a ser mais eficiente dependerá principalmente do uso mais ou menos pleno que farão do conhecimento existente. Isso, por sua vez, depende do sucesso que obteremos ao pôr à disposição de uma única autoridade central todo o conhecimento que deverá ser usado, o qual, inicialmente estava disperso entre vários diferentes indivíduos, ou da transmissão aos indivíduos desse conhecimento adicional que necessitam, a fim de habilitá-los a combinar seus planos com os dos outros.

\section{III}

Nesse ponto, ficará evidente de pronto que a posição tornar-se-á diversa dependendo dos diferentes tipos de conhecimento. A resposta à nossa questão girará, por conseguinte, em torno da relativa importância dos diferentes tipos de conhecimento: aqueles mais suscetíveis a estar à disposição de indivíduos particulares, e aqueles que devemos esperar com mais confiança encontrar em uma autoridade composta de experts devidamente escolhidos. Se é hoje amplamente pressuposto que esta última categoria estará em melhor posição, isto é porque um tipo de conhecimento, a saber, o conhecimento científico, ocupa agora um lugar tão proeminente na imaginação pública que tendemos a esquecer que não é o único tipo relevante. Pode-se admitir que, na medida em que o conhecimento científico está envolvido, um corpo de experts devidamente escolhidos pode estar em melhor posição para comandar todo o melhor conhecimento disponível - embora isso esteja apenas deslocando a dificuldade para o problema de selecionar os experts. O que gostaria de salientar é que, mesmo admitindo que esse problema possa ser facilmente resolvido, ele é apenas uma pequena parte de um problema mais amplo.

Hoje é quase heresia sugerir que o conhecimento científico não é a soma de todo o conhecimento. No entanto, um pouco de reflexão mostrará que há, além de toda dúvida, um corpo de conhecimento muito importante, mas não organizado, que não poderia ser chamado científico no sentido de conhecimento de regras gerais: o conhecimento das circunstâncias particulares de tempo e espaço. É por esta razão que praticamente todo indivíduo tem alguma vantagem sobre todos 
os outros, por possuir informações exclusivas sobre qual bom uso pode ser feito; uso que poderá ser realizado apenas se as decisões correlativas forem deixadas para o indivíduo decidir, ou se forem feitas com sua ativa cooperação. Precisamos lembrar apenas o quanto nós temos de aprender em qualquer ocupação, mesmo depois de termos completado nossa formação teórica; quão grande é a parte de nossa vida de trabalho que gastamos aprendendo tarefas específicas; e o quão valioso bem é, em todas as posições sociais, o conhecimento sobre as pessoas, condições locais e circunstâncias especiais. Conhecer e pôr em uso seja uma máquina ainda não plenamente empregada, seja a habilidade de determinada pessoa que poderia ser mais bem utilizada, ou ainda ter informação de um estoque excedente que poderia ser aproveitado durante a interrupção do fornecimento de determinado bem é, socialmente, tão útil quanto o conhecimento das melhores técnicas alternativas. $\mathrm{O}$ marinheiro que ganha a vida aproveitando as viagens que, de outra feita, estariam total ou parcialmente vazias nos navios itinerantes, ou o corretor de imóveis cujo conhecimento pleno é quase exclusivamente a respeito de oportunidades temporárias, ou o arbitragista que ganha a partir de diferenças locais nos preços das commodities, são exemplos de funções eminentemente úteis que se baseiam em um conhecimento especial das circunstâncias do momento fugaz, as quais são desconhecidas pelos outros.

É um fato curioso que esse tipo de conhecimento seja visto hoje em dia com uma espécie de desprezo e quem quer que dele se beneficie, superando os mais bem dotados de conhecimento teórico ou técnico, vê a conduta tida como vergonhosa. Obter vantagem por ter um conhecimento melhor das tecnologias de comunicação ou de transporte é visto, por vezes, como algo quase desonesto, embora fazê-lo, explorando as melhores oportunidades disponíveis, seja tão importante para a sociedade quanto utilizar as mais recentes descobertas científicas. Este preconceito tem afetado em medida considerável a atitude em relação ao comércio em geral, se comparada com a atitude em relação à produção. Mesmo os economistas que se consideram definitivamente imunes às cruéis falácias materialistas do passado cometem, constantemente, o mesmo erro quando tratam de atividades voltadas para a aquisição de tal conhecimento prático aparentemente porque na sua hierarquia das coisas todo conhecimento desse gênero é tido como "dado". A ideia geral parece agora ser de que todo conhecimento desse tipo deva estar prontamente, como se deduz, à disposição de todos, e a acusação de irracionalidade levantada contra a ordem econômica existente, muitas vezes, está baseada no fato de que o conhecimento não se encontra assim tão disponível. Esse ponto de vista desconsidera o fato de que o método pelo qual tal conhecimento poderia ser tão largamente disponibilizado é precisamente o problema para o qual temos de encontrar uma resposta.

\section{IV}

Se está na moda hoje minimizar a importância do conhecimento das circunstâncias particulares de tempo e espaço, isto está intimamente relacionado com a importância mínima que agora é atribuída à mudança dentro dessas duas mesmas categorias. Com efeito, há alguns pontos em que as hipóteses elaboradas (geralmente apenas de forma implícita) pelos "planejadores" diferem das de seus oponentes, tanto a respeito do significado como a frequência das mudanças necessárias que alterarão substancialmente os planos de produção. $\mathrm{Ob}-$ viamente, se planos econômicos detalhados pudessem ser traçados com antecedência por períodos ligeiramente longos e, em seguida, executados de forma rigorosa, nenhuma outra decisão econômica de importância seria necessária e, com isso, a tarefa de elaborar um plano abrangente para governar todas as atividades econômicas seria muito menos formidável.

Talvez fosse importante ressaltar que problemas econômicos surgem sempre, e apenas em consequência da mudança. Enquanto 
as coisas continuarem como antes, ou pelo menos como estavam previstas, e não surgir nenhum novo problema que requeira uma decisão, não teremos necessidade de fazer um novo plano. A crença de que mudanças, ou pelo menos ajustes cotidianos, se tornaram menos importantes nos tempos modernos sugere que os problemas econômicos também se tornaram menos importantes. Essa crença na importância decrescente da mudança é, por tal razão, sustentada geralmente pelas mesmas pessoas que argumentam que a importância das reflexões econômicas tem sido deixada de lado pela crescente importância do conhecimento tecnológico.

Seria verdadeiro dizer que com o elaborado aparato da produção moderna, as decisões econômicas fazer-se-iam necessárias apenas em grandes períodos, como na ocasião da construção de uma nova fábrica ou na introdução de um novo processo? Seria verdade que, uma vez que uma usina tenha sido construída, todo o resto seria mais ou menos mecânico, determinado pela natureza da planta, e haveria pouco espaço para mudanças de adaptação às circunstâncias sempre em transformação de acordo com o momento?

A crença bastante difundida nessa afirmativa não é, tanto quanto possa verificar, corroborada pela experiência prática do empresário. Em qualquer indústria competitiva - e somente tal indústria poderia servir como teste - a tarefa de manter o custo sem aumentos requer esforço constante, e absorve grande parte da energia do gestor. Como é fácil para um gestor ineficiente dissipar os diferenciais do quais depende a rentabilidade, e como é possível, com o mesmo aparato técnico, produzir com uma grande variedade de custos: esses estão entre os lugares comuns da experiência empresarial, os quais não parecem ser igualmente familiares ao estudo do economista. A própria força, constantemente manifestada por produtores e engenheiros, de desejar poder seguir sem os entraves dos custos financeiros, é um testemunho eloquente de quanto tais fatores influenciam em seu trabalho diário.
Uma das razões pelas quais os economistas são cada vez mais suscetíveis a esquecer das frequentes, porém pequenas, mudanças que compõem todo o quadro econômico seria, provavelmente, a preocupação crescente com os agregados estatísticos, que revelam muito mais a estabilidade do que os movimentos do detalhe. A comparativa estabilidade dos agregados não pode, contudo, ser vista - conforme os estatísticos ocasionalmente parecem estar inclinados a fazer - a partir da "lei dos grandes números" ou da compensação mútua das mudanças aleatórias. O número de elementos com os quais temos de lidar não é grande o suficiente para que tais forças acidentais produzam estabilidade. O fluxo contínuo de bens e serviços é mantido por ajustes constantes e deliberados, por novas disposições feitas todos os dias à luz de circunstâncias não conhecidas no dia anterior, por B intervindo quando $\mathrm{A}$ falha em entregar. Mesmo a grande e altamente mecanizada indústria continua o seu trabalho, em grande parte por causa de um ambiente em que se podem remediar todos os tipos de necessidades inesperadas: telhas para o telhado, papéis e formulários para os escritórios, e os mil e um tipos de equipamentos que não podem ser autossupridos, e cujos planos de funcionamento da indústria exigem que estejam facilmente disponíveis no mercado.

Esse é, talvez, o ponto em que deva mencionar, brevemente, que o tipo de conhecimento com que tenho me preocupado é o conhecimento de um tipo que pela própria natureza não pode entrar nas estatísticas e, portanto, não pode ser transmitido para nenhuma autoridade central em relatórios estatísticos. As estatísticas que essa autoridade central teria que usar teriam de ser alcançadas precisamente pela abstração de pequenas diferenças entre as coisas, ao agrupar, como recursos de um tipo, itens que diferem quanto à localização, qualidade, e outros elementos, de uma maneira que sejam muito importantes para a decisão específica. Daí resulta que o planejamento central com base em informações estatísticas não pode, por natureza, 
tomar diretamente em consideração as circunstâncias de tempo e espaço, e que o planejador central terá de encontrar, de um jeito ou de outro, uma forma em que as decisões delas dependentes sejam deixadas para o "agente local".

\section{V}

Se podemos concordar que o problema econômico da sociedade gira em torno principalmente da adaptação rápida a mudanças em circunstâncias particulares de tempo e espaço, parece seguir-se que as decisões finais devem ser deixadas para as pessoas que estão familiarizadas com essas circunstâncias. Estas conhecem diretamente as mudanças relevantes e os recursos imediatamente disponíveis para resolvê-las. Não podemos esperar que esse problema vá ser resolvido comunicando primeiramente todo aquele conhecimento a um comitê central, o qual, por sua vez, depois de integrar todo conhecimento, expede suas ordens. Devemos resolvê-lo por alguma forma de descentralização; mas isso responde apenas em parte ao nosso problema. Precisamos de descentralização, porque só assim podemos assegurar que o conhecimento das circunstâncias particulares de tempo e espaço será prontamente utilizado. Contudo, o "agente local" não pode decidir unicamente com base no seu conhecimento limitado, porém íntimo, dos fatos pertencentes aos arredores próximos. Há ainda o problema de como lhe comunicar as informações mais profundas, de que precisa para adequar suas decisões à inteira configuração de mudanças do sistema econômico mais amplo.

De quanto conhecimento ele precisaria para realizar isso com sucesso? Quais são os eventos que aconteceriam além do horizonte de seu imediato conhecimento, e quantos deles precisaria conhecer?

Não há quase nada que aconteça em algum lugar do mundo que não possa ter um efeito sobre a decisão que este agente deve fazer; mas não precisa conhecer estes eventos sob esta óptica, nem todos os seus efeitos. Não lhe importa por que, no momento específico, mais parafusos de certo tamanho são mais procurados do que parafusos de outros tamanhos, por que sacos de papel são mais facilmente disponibilizados do que sacos de lona, ou por que a mão de obra qualificada, ou certas ferramentas do maquinário, tornaram-se mais difíceis de se obter no momento. Tudo o que é significativo para ele é saber quão mais ou menos difícil de obter se tornaram, comparando-os com outras coisas que também lhes envolvem, ou quanto mais ou menos são urgentemente desejados os objetos alternativos que ele produz ou usa. É sempre uma questão a respeito da relativa importância das coisas particulares com as quais ele está envolvido; e as causas que alteram a sua importância relativa, por sua vez, não são de seu interesse, além do efeito sobre as coisas concretas de seu próprio ambiente.

É nesta relação que o que chamo de "cálculo econômico" (ou Lógica Pura da Escolha) nos ajuda, pelo menos, por analogia, a ver como esse problema pode ser solucionado, e de fato está sendo solucionado, pelo sistema de preços. Mesmo aquela única mente controladora, em posse de todos os dados de input para alguns pequenos e autossuficientes sistemas econômicos, não iria - a cada vez que algum pequeno ajuste na alocação de recursos precisasse ser feito - passar explicitamente por todas as relações entre fins e meios que poderiam eventualmente ser afetadas. Em verdade, é a grande contribuição da Lógica Pura da Escolha que demonstrou, de forma conclusiva, que mesmo tal mente tão simples poderia resolver esse tipo de problema apenas por meio da construção e do uso constante de taxas de equivalência ("valores", ou "taxas marginais de substituição"). Isto é, atribuindo a cada tipo de recurso escasso um índice numérico, que não pode ser derivado de nenhuma propriedade dessa coisa particular, mas que reflete, ou no qual é condensado, o seu significado próprio em vista de toda estrutura de meio-fim. Em qualquer pequena mudança, ele terá de considerar apenas esses 
índices quantitativos (ou "valores"), em que toda a informação relevante é concentrada; e, ao ajustar as quantidades uma por uma, pode reorganizar de forma apropriada suas disposições, sem ter de resolver o quebra-cabeças inteiro $a b$ initio ou sem precisar examiná-lo em todas as suas ramificações de uma vez só.

Fundamentalmente, em um sistema no qual o conhecimento dos fatos relevantes está disperso entre muitas pessoas, os preços podem agir para coordenar as ações separadas de diferentes pessoas, da mesma forma como valores subjetivos ajudam o indivíduo a coordenar as partes de seu plano. Vale a pena contemplar por um momento uma instância de ação do sistema de preços muito simples e lugar-comum para ver o que exatamente ela alcança. Suponhamos que em algum lugar do mundo surja uma nova oportunidade para utilizar alguma matéria-prima, por exemplo, o estanho, e ainda que uma das fontes de abastecimento de estanho tenha sido eliminada. Não importa para nosso intento - e é significativo que não importe - qual dessas duas causas tornou o estanho mais escasso. Tudo que os usuários de estanho precisam saber é que uma parte do estanho que eles costumavam consumir é agora mais lucrativamente empregada em outro lugar e que, em consequência disso, precisam economizar estanho. Não há nem mesmo a necessidade, para a grande maioria deles, de saber onde a necessidade mais urgente surgiu, ou por que há outras necessidades pelas quais eles precisam armazenar tal bem de consumo. Se apenas alguns deles conhecem diretamente a nova demanda, e deslocam seus recursos para ela; e se as pessoas que estão cientes da nova lacuna então criada, por sua vez, preencham-na a partir de outras fontes, o efeito será rapidamente propagado por todo o sistema econômico e influenciará não só todos os usos do estanho, mas também aqueles de substitutos e de substitutos dos substitutos , e ainda o fornecimento de todas as coisas feitas de estanho, seus substitutos, e assim por diante; e tudo isso sem a grande maioria dos instrumentais que provocam essas substituições, sem saber nada sobre a causa original dessas mudanças. O todo age como um mercado, não porque algum de seus membros examine todo o campo, mas porque seus campos individuais de visão, limitados, sobrepõem-se o suficiente para que, por meio de muitos intermediários, a informação relevante seja comunicada a todos. O simples fato de que há um preço para toda mercadoria - ou melhor, que os preços locais estejam inter-relacionados de uma maneira determinada pelo custo do transporte e etc. - tornaria possível, mas apenas conceitualmente, a solução de chegar lá através de uma única mente, possuidora toda a informação outrora dispersa, de fato, entre todas as pessoas envolvidas no processo.

\section{VI}

Temos de olhar para o sistema de preços como esse mecanismo que descrevemos para a comunicação de informações, se quisermos compreender a sua real função. Esta, naturalmente, cumpre-se menos perfeitamente na medida em que os preços crescem mais rigidamente (mesmo quando os preços cotados tornam-se bastante rígidos, as forças que operam por intermédio da mudança de preços, contudo, ainda operam até certo grau através das mudanças em outros termos do contrato). O fato mais significativo sobre esse sistema é a economia de conhecimento com que opera, ou quão pouco os participantes individuais precisam conhecer a fim de serem capazes de tomar a ação correta. De forma abreviada, por uma espécie de símbolo, apenas a informação mais essencial é passada e passada apenas aos envolvidos. E mais do que uma metáfora descrever o sistema de preços como uma espécie de maquinaria para o registro de mudanças, ou um sistema de telecomunicações que permite aos produtores individuais, meramente observando o movimento de alguns indicadores (como um engenheiro pode observar os ponteiros de alguns mostradores), ajustar suas atividades às mudanças, sobre as quais nunca poderá 
conhecer mais do que é refletido no movimento dos preços.

Naturalmente, esses ajustes provavelmente nunca serão "perfeitos" no sentido em que o economista os conceberia em sua análise de equilíbrio, mas temo que os nossos hábitos teóricos de abordar o problema, supondo um conhecimento mais ou menos perfeito da parte de quase todas as pessoas, já nos tornou, de alguma forma, cegos para a verdadeira função do mecanismo de preços, e nos levou a aplicar padrões, a bem de verdade, enganadores, ao julgar sua eficiência. A maravilha é que em um caso como este, de escassez de uma matéria-prima, sem a emissão de qualquer pedido, sem mais do que talvez um punhado de pessoas conhecendo a causa, dezenas de milhares de pessoas, cuja identidade não pôde antes ser verificada em meses de investigação, acabam usando o material, ou seus produtos, com mais moderação; ou seja, passam a se mover na direção certa. Tal quadro ainda permanece uma maravilha, mesmo se, num mundo em constante mudança, nem todos vão acertar tão perfeitamente, tendo suas taxas de lucro sempre mantidas em nível uniforme ou "normal".

Utilizei deliberadamente a palavra "maravilha" para chocar o leitor, tirando-o de sua complacência pela qual, muitas vezes, o trabalho desse mecanismo nos passa despercebido. Estou convencido de que, se fosse resultado de um projeto humano intencional, e se as pessoas fossem guiadas pelas mudanças de preços, entendendo que as suas decisões têm significado muito além do seu objetivo imediato, esse mecanismo teria sido aclamado como um dos maiores triunfos da mente humana. O seu infortúnio é duplicado, por não ser o produto do gênio humano e que as pessoas guiadas por ele normalmente não sabem por que são inclinadas a fazer o que fazem. Aqueles que, no entanto, clamam por uma "direção consciente" - e que não podem acreditar que algo que evoluiu sem projeto (e mesmo sem a nossa compreensão) possa resolver problemas que não fomos capazes de resolver conscientemente - devem lembrar-se do seguinte: o problema é justamente como estender o período de utilização que fazemos de recursos além do período de controle da mente de alguém e, portanto, como dispensar a necessidade do controle consciente; e como fornecer estímulos para que os indivíduos ponham em prática ações desejáveis sem que ninguém lhes dite o que fazer.

O problema que encontramos aqui não é de forma alguma peculiar à economia, mas surge em inter-relação com quase todos os fenômenos verdadeiramente sociais, com a linguagem e com a maior parte da nossa herança cultural, e constitui realmente o problema teórico central de toda ciência social. Como Alfred North Whitehead (1861-1947) disse em outra ocasião: "É um truísmo profundamente errado, repetido por todas as cartilhas e por pessoas eminentes ao proferir discursos, que devemos cultivar o hábito de pensar no que estamos fazendo. O caso é exatamente o oposto. A civilização avança ao ampliar o número das operações importantes que podemos realizar sem pensar nelas". Isso é de profundo significado no campo social. Fazemos uso constante de fórmulas, símbolos e regras cujo significado não compreendemos, e por intermédio de seu uso que nos valemos da assistência daquele conhecimento que, individualmente, não possuímos. Desenvolvemos essas práticas e instituições ao fundar nossas construções sobre hábitos e instituições, que provaram ser bem sucedidos em sua própria esfera e que, por sua vez, tornaram-se a base da civilização que construímos.

O sistema de preços é apenas uma daquelas formações que o homem aprendeu a usar (embora ainda esteja muito longe de ter aprendido como fazer um melhor uso dele) depois de ter tropeçado sem compreendê-lo. Por meio dele, não só a divisão de trabalho, mas também a utilização coordenada de recursos baseada em um conhecimento igualmente compartilhado, tornou-se possível. As pessoas que gostam de ridicularizar qualquer sugestão sobre o fato das coisas serem de tal forma e distorcem, em geral, o argumento, insinuando que afirmamos ter havido algum 
milagre para que o sistema tenha crescido espontaneamente, sistema este que seria o mais adequado para a civilização moderna. A direção é inversa: o homem foi capaz de desenvolver tamanha divisão do trabalho, que é a base da civilização, porque acabou esbarrando em um método que tornou isso possível. Se não tivesse feito isso, talvez tivesse desenvolvido algum outro tipo de civilização, completamente diferente, algo como o "Estado" dos cupins, ou algum outro tipo totalmente inimaginável. Tudo o que podemos dizer é que ninguém ainda conseguiu projetar um sistema alternativo em que certas características do sistema existente, estimadas mesmo por aqueles que mais violentamente o atacam, possam ser preservadas - tal como, em particular, a gama de atividades variada em que o indivíduo pode escolher uma ou mais atividades para si e, em consequência disso, usar livremente os próprios conhecimento e habilidade.

\section{VII}

Felizmente, sob muitos aspectos, a discussão sobre a indispensabilidade do sistema de preços para todo cálculo racional, em uma sociedade complexa, já não é realizada exclusivamente entre campos que sustentam diferentes pontos de vista políticos. A tese de que sem o sistema de preços não poderíamos preservar uma sociedade baseada em tal divisão do trabalho tão ampla como a nossa foi saudada com um grito de escárnio quando proposta por Ludwig von Mises (1881-1973) há alguns anos atrás. Hoje as dificuldades que alguns ainda encontram para aceitá-la não são mais políticas, e isso contribui para uma atmosfera muito mais propícia à discussão razoável. Quando encontramos Leon Trotsky (1879-1940) argumentando que "a contabilidade econômica é impensável sem as relações de mercado"; quando o professor Oskar Lange (19041965) promete ao professor von Mises uma estátua nos corredores de mármore da futura Diretoria de Planejamento Central; e quando o professor Abba P. Lerner (1903-1982) redescobre Adam Smith (1723-1790) e enfatiza que a utilidade essencial do sistema de preços consiste em induzir o indivíduo, que busca o próprio interesse, a fazer o que é de interesse geral, as diferenças não podem mais ser atribuídas ao preconceito político. A dissidência remanescente parece se dever claramente às diferenças puramente intelectuais, e mais particularmente metodológicas.

Uma declaração recente de Joseph Schumpeter (1883-1950) em seu Capitalism, Socialism and Democracy [Capitalismo, Socialismo e Democracia] oferece uma clara ilustração de uma das diferenças metodológicas que tenho em mente. Seu autor é famoso entre aqueles economistas que se aproximam dos fenômenos econômicos na luz de um determinado ramo do positivismo. Para ele, esses fenômenos aparecem consequentemente como quantidades objetivamente dadas de commodities, afetando-se diretamente umas às outras, quase, ao que parece, sem qualquer intervenção de mentes humanas. É somente diante desse contexto que posso explicar o seguinte pronunciamento (que é, para mim, surpreendente): quando o professor Schumpeter defende que a possibilidade de um cálculo racional na ausência de mercados para os fatores de produção segue para o teórico "da proposição elementar que os consumidores, ao avaliar ('requerer') bens de consumo ipso facto, também avaliam os meios de produção que entram na produção desses bens" $"$.

\footnotetext{
${ }^{3}$ SCHUMPETER, Joseph. Capitalism, Socialism and Democracy. New York: Harper \& Bros, 1942. p. 175. Professor Schumpeter é, creio eu, também o autor original do mito de que Vilfredo Pareto (1948-1923) e Enrico Barone (1859-1924) teriam "resolvido" o problema do cálculo socialista. O que eles, e muitos outros, fizeram foi apenas indicar as condições que uma alocação racional de recursos teria de satisfazer, e de salientar que essas eram, em essência, as mesmas que as condições de equilíbrio de um mercado competitivo. Isso é algo completamente diferente de mostrar como a alocação de recursos, ao satisfazer essas condições, poderia ser encontrada na prática. $\mathrm{O}$ próprio Pareto (de quem Barone tomou praticamente tudo o que tinha a dizer), longe de afirmar ter resolvido o problema
} 
Tomada literalmente, esta afirmação é simplesmente falsa. Os consumidores não fazem nada do tipo. O que o professor Schumpeter "ipso facto" quer dizer, de forma presumível, é que a avaliação dos fatores de produção está implícita na, ou segue necessariamente da avaliação dos bens de consumo. Mas isso, também, não está correto. Implicação é uma relação lógica que pode ser apenas dita de forma significativa de proposições simultaneamente presentes a uma e única mente. É evidente, contudo, que os valores dos fatores de produção não dependem somente da valorização dos bens de consumo, mas também das condições de oferta dos vários fatores de produção. Apenas numa mente em que todos estes fatos fossem simultaneamente conhecidos é que a resposta seguiria necessariamente deles. $\mathrm{O}$ problema prático, no entanto, surge precisamente porque esses fatos nunca são dados de tal forma a uma única mente, e porque, em consequência, é necessário que, na solução do problema, seja usado o conhecimento que está disperso entre muitas pessoas.

O problema não é, portanto, de forma alguma resolvido se pudermos mostrar que todos os fatos, caso fossem conhecidos por uma única mente (como hipoteticamente os assumimos como dados ao economista observador), determinariam unicamente a solução; ao contrário, devemos mostrar como uma solução é produzida pelas interações das pessoas, sendo que cada uma delas possui apenas um conhecimento parcial. Assumir que todo o conhecimento seja dado a uma única mente, da mesma forma que assumimos que ele seja dado a nós, assim como as explicações dos economistas, é pôr o pro-

prático, nega de fato, e de modo explícito, que possa ser resolvido sem a ajuda do mercado. Conferir: PARETO, V. Manuel d'economie pure. Paris: Giard et Brière, $2^{a} \mathrm{Ed}$., 1927. p. 233-34. A passagem relevante é citada em uma tradução inglesa no início do meu artigo: HAYEK, F. A. von. Socialist Calculation: The Competitive 'Solution'. Economica, v.8, n. 26, 125. (new ser., 1940) [O texto em questão foi re-editado como o oitavo capítulo do livro Individualism \& Economic Order (N. do T.)]. blema de lado, e ignorar tudo o que for importante e significativo no mundo real.

Que um economista de nível como o professor Schumpeter tenha, portanto, caído na armadilha que a ambiguidade do termo "datum" põe para os incautos, dificilmente pode ser algo explicado como um simples erro. Isso sugere, ao invés, que há algo fundamentalmente errado com uma abordagem que ignore de modo recorrente uma parte essencial dos fenômenos com os quais temos de lidar: a imperfeição inevitável do conhecimento do homem, e a consequente necessidade de um processo pelo qual o conhecimento seja constantemente comunicado e adquirido. Qualquer abordagem, como a de grande parte da economia matemática com suas equações simultâneas que, na verdade, parte do pressuposto de que o conhecimento das pessoas corresponde aos fatos objetivos da situação, deixa sistematicamente de fora o que é nossa principal tarefa explicar. Estou longe de negar que, em nosso sistema, a análise de equilíbrio teria alguma função útil a realizar; mas, quando se chega ao ponto em que ela passa a enganar alguns de nossos mais importantes pensadores, fazendo-os acreditar que a situação descrita teria relevância direta para a solução dos problemas práticos, é tempo propício para lembrarmos de que ela não lida de nenhuma maneira com o processo social, e que não é mais do que uma útil preliminar para o estudo do principal problema.cos 